\title{
Final de uma década, reflexos socioeconômicos: a criação e atuação da Justiça Federal no norte do RS - 1980
}

\author{
End of decade, socio-economical reflexes: the creation and actions of the Federal Justice \\ in Northern RS - 1980
}

Final de una década, reflejos socioeconómicos: la creación y actuación de la Justicia Federal en el Norte del RS - 1980

Ironita Policarpo Machado*

\section{Resumo}

O artigo tem por objetivo contextualizar historicamente a criação e atuação da Justiça Federal em Passo Fundo, na década de 1980. Para tal, realizou-se uma leitura da história da Justiça Federal, como um órgão do Poder Judiciário, centrando-se na análise de conjuntura política e econômica da Região Sul para interpretar os motivos da interiorização da Justiça Federal. Busca-se compreender o contexto histórico e os sentidos do poder da Justiça Federal, bem como a sua abrangência, realizando entrevistas com sujeitos que participaram da criação da Justiça Federal Subseção de Passo Fundo, e com a análise do conteúdo de documentos institucionais e dos registros dos processos da década de 1980, a fim de estabelecer as tipologias dos litígios e as relações com o final de uma década como ruptura ou continuidade de uma conjuntura histórica.

Palavras-chave: Justiça Federal. Processos judiciais. Conjuntura histórica e socioeconômica.

\section{Introdução}

A questão da interiorização da Justiça Federal no Rio Grande do Sul suscita alguns questionamentos sobre suas motivações, tais como: quais tipos de demanda se fizeram presentes no período? Que tipo de reivindicação os autores dos litígios faziam? Quais as relações que podem ser estabelecidas entre o processo de interiorização da Justiça Federal com o final do regime militar? Essas interrogações estão no centro da nossa discussão inicial, para que possamos ampliar os estudos sobre o judiciário inserido no processo de transição socioeconômica do final da década de 1980, também marcada pela transição política no país.

\footnotetext{
Professora do Curso de Licenciatura e do Programa de Pós-Graduação em História da Universidade de Passo Fundo. E-mail: iropm@upf.br.
}

Recebido em 02/09/2014 - Aprovado em 25/03/2015 http://dx.doi.org/10.5335/hdtv.15n.1.5283 
Contextualizacão da Justica Federal

\section{(Brasil - Rio Grande do Sul - Região Norte)}

A relação que envolve a Justiça Federal como um órgão do Poder Judiciário e os fatores que motivaram sua interiorização devem ser pensados sob a premissa de que os motivos estão relacionados a questões políticas, econômicas e sociais. Assim, é necessário refletir acerca de alguns dados que ajudarão a desenvolver este raciocínio.

A Justiça Federal foi criada, no Brasil, em 1890, pelo Decreto ${ }^{\circ} 848$, de 11 de outubro, com a competência de julgar processos de empresas federais, fundações ou de qualquer natureza, autoras ou rés. Pode-se dizer que, no período em que ela foi criada, o Brasil passava por uma fase de transição política, de Império para República e, separando o Estado da Igreja, segundo Campos Salles, o sistema judicial era:

O organismo judiciário no systema federativo, systema que repousa essencialmente sobre a existência de duas soberanias na tríplice esphera do poder público, exige para o seu regular funcionamento uma demarcação clara e positiva, traçando os limites entre a jurisdicção federal e a dos Estados, de tal sorte que o domínio legítimo de cada uma destas soberanias seja rigorosamente mantido e reciprocamente respeitado (SALLES, 1890, p. 14).

Era necessário que o país tivesse uma jurisdição com limites entre os órgãos federal e estadual, limites esses que fizessem com que a sociedade compreendesse as suas funções e o seu funcionamento, podendo então fazer um trabalho com resultados positivos.
No ano de 1937, no governo ditatorial de Getúlio Vargas, com a nova Constituição, é extinta a Justiça Federal (JF), tornando, assim, o Poder Judiciário uma justiça única, retirando as seções estaduais da JF. Uma nova regulamentação da Justiça ocorreu somente em 1966, com a Lei $n^{\circ} 5.010$, de 30 de maio, marcando a institucionalização do regime militar, que decretava que cada estado formaria uma seção judiciária, sendo classificadas em cinco regiões: $1^{a}$ Região - Região Centro-Oeste, Região Norte e parte da Região Nordeste: Acre, Amapá, Amazonas, Bahia, Distrito Federal, Goiás, Minas Gerais, Pará, Piauí, Rondônia, Roraima e Tocantins; $2^{\mathrm{a}}$ Região - Parte da Região Sudeste: Espírito Santo e Rio de Janeiro; $3^{\text {a }}$ Região - Parte da Região Sudeste: São Paulo; $4^{\mathrm{a}}$ Região - Região Sul: Paraná, Rio Grande do Sul e Santa Catarina; $5^{a}$ Região - Parte da Região Nordeste: Alagoas, Ceará, Paraíba, Pernambuco (compreendendo o território de Fernando de Noronha), Rio Grande do Norte e Sergipe.

Desde sua criação, a Justiça Federal só abrangia as capitais do Brasil, e essa situação gerava descontentamento e críticas da sociedade, pois muitos cidadãos não tinham condições de acesso aos serviços jurisdicionais. Então, a partir do ano de 1987, deu-se início ao processo de interiorização da Justiça, com a criação de 183 novas varas em todo o país, tornando-a mais acessível aos seus jurisdicionados $^{1}$. Atualmente, a Justiça Federal do Rio Grande do Sul conta com 21 subseções judiciárias, sediadas nos municípios de Porto Alegre, Canoas, Novo Hamburgo, Caxias do Sul, Bento Gonçalves, Santa Cruz do Sul, Lajeado, Passo Fundo, Santa Maria, Cachoeira do Sul, Erechim, Carazinho, Cruz 
Alta, Santa Rosa, Santo Ângelo, Santana do Livramento, Uruguaiana, Bagé, Pelotas, Rio Grande e Santiago.

A subseção da Justiça Federal do Rio Grande do Sul em Passo Fundo foi criada no ano de 1987, sendo que ela, juntamente com Rio Grande, Santo Ângelo e Santa Maria, foram as primeiras a serem criadas. Atualmente, no Rio Grande do Sul, há 24 subseções dentre as quais Passo Fundo, que engloba 31 municípios da regiãoº ${ }^{2}$ Em termos de funcionamento, a subseção de Passo Fundo abriga xhoje: a $1^{\text {a }}$ Vara Federal e o Juizado Especial Federal Cível Adjunto; a $2^{\mathrm{a}}$ Vara Federal e o Juizado Especial Federal Cível Adjunto; a Vara Federal Criminal e de Execuções Fiscais com Juizado Especial Federal (JEF) Criminal Adjunto; e Vara do Juizado Especial Federal Previdenciário.

Figura 1: Mapa - Rio Grande do Sul, com as cidades sedes da Justiça Federal e suas Subseções

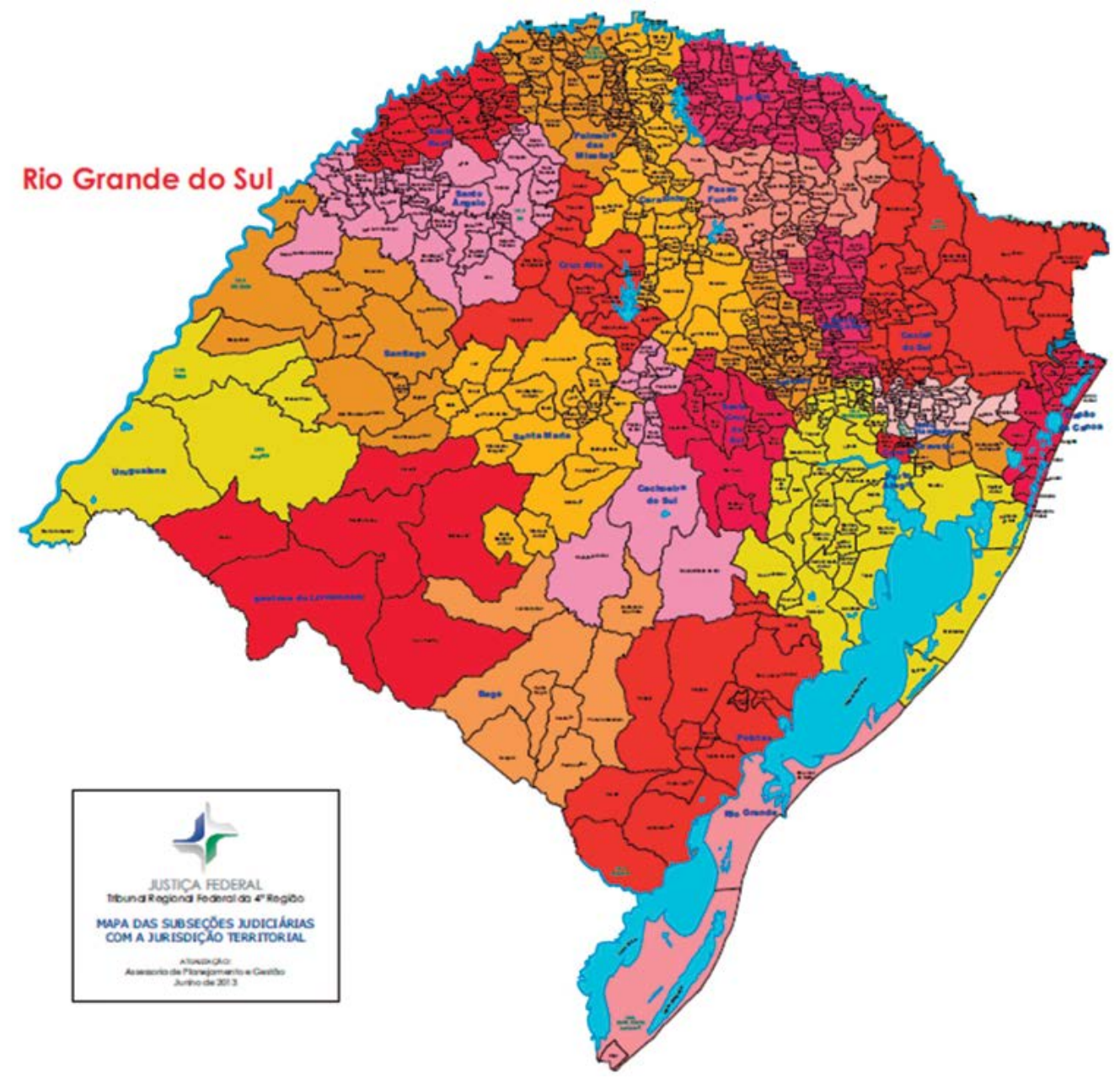

Fonte: Justiça Federal do Rio Grande do Sul. 
O município de Passo Fundo, localizado no norte do estado, faz parte das primeiras subseções criadas no Rio Grande do Sul, englobando, como já mencionado, 31 municípios. Todos os anos essa estrutura sofre alterações, com a criação de novas subseções, com o aumento da demanda dos processos ou com a necessidade de ter um espaço no qual se represente a justiça em determinadas cidades. Como se constata, a Justiça Federal tem sedes no país inteiro, englobando, assim, todos os estados, cidades e municípios, buscando melhorar o funcionamento da jurisdição do país.

\section{Contextualização histórica do período da criação da subseção da Justiça Federal de Passo Fundo}

Nas últimas décadas do século XX, o Brasil, assim como o Rio Grande do Sul e Passo Fundo, passou por um momento de ruptura histórica com muitas transformações: a globalização do mercado, os sucessivos confrontos étnicos e religiosos, a crescente desigualdade social, a constante mudança na tecnologia, gerando vários problemas de desemprego, mudaram a estrutura das cidades relacionadas à sociedade.

A turbulência no ambiente econômico brasileiro da década de 1980 originou-se na década anterior, em função da expansão do endividamento externo do governo. Os anos 1970 ofereceram facilidades de obtenção de financiamento no mercado internacional. A oferta de crédito elevou-se por meio de aportes de recursos dos países exportadores de petróleo quando esses passaram a aplicar seus saldos comerciais no mercado financeiro internacional.

O resultado do excesso de liquidez nesse mercado foi o aumento da oferta de empréstimos e a queda nos juros. Assim, para a obtenção de financiamento para os programas de investimentos, entre eles o do II Plano Nacional de Desenvolvimento, o Brasil se endividou.

No entanto, a partir de 1978, o cenário começou a mudar em função de uma grande elevação da taxa de juros no mercado financeiro internacional. Essa alteração na trajetória dos juros acarretou aumento do custo da dívida brasileira. O cenário se agravou em 1982, quando o México declarou moratória de sua dívida externa. Esse movimento provocou uma redução na oferta de crédito e o encarecimento das taxas de juros internacionais, o que impediu a renovação de empréstimos no mercado financeiro internacional.

Assim, a elevação nas taxas de juros e a redução do crédito no mercado internacional recaíram sobre o governo federal, que também assistiu a sua receita advinda dos impostos reduzir pelo efeito do processo inflacionário. Ainda, as contas do governo apresentaram um nível maior de degradação por problemas fiscais advindos do aumento de seus gastos correntes.

A crise da dívida impôs um forte ajuste fiscal. Com a crise da dívida, o Estado reduziu seu nível de investimento. Tendo em vista a grande participação do investimento estatal na ampliação da infraestrutura econômica e no estímulo da atividade em setores básicos (como a indústria de bens de capital), o resultado dessa retração de investimentos foi a estagnação do crescimento 
econômico, que se projetou pelas décadas de 1980 e 1990.

Na Tabela 1, pode-se verificar as taxas de crescimento médias do PIB e do PIB per capita, nas últimas quatro décadas. A década de 1980 destaca-se por apresentar as menores taxas médias de crescimento do PIB $(1,4 \%)$ e do PIB per capita $(-0,7 \%)$. Importante destacar que, segundo esses dados, que foram coletados do sítio eletrônico do Instituto Brasileiro de Geografia Estatítica (IBGE) (que é o responsável pelo seu cálculo), em 2014, e que condizem com a sistematização de Neri (2014), o PIB per capita reduziu-se em mais de $12 \%$, entre 1980 e 1983, o maior recuo registrado pelo país.

Tabela 1: Taxa de crescimento média do PIB e PIB per capita dos anos de 1970 a 2000

\begin{tabular}{l|r|r}
\cline { 2 - 3 } \multicolumn{1}{c|}{} & \multicolumn{1}{|c|}{ PIB } & PIB per capita \\
\hline $70 \mathrm{~s}$ & $8,6 \%$ & $6.0 \%$ \\
$80 \mathrm{~s}$ & $1,4 \%$ & $-0,7 \%$ \\
$90 \mathrm{~s}$ & $2,8 \%$ & $1,5 \%$ \\
$00 \mathrm{~s}$ & $3,3 \%$ & $2,1 \%$ \\
\hline
\end{tabular}

Fonte: Neri 2014 apud Bacha; Bonelli, 2004.

Outro aspecto relevante ao ambiente econômico dos anos 1980 refere-se aos elementos que comandam o crescimento da economia. O consumo das famílias tem papel proeminente na determinação do ritmo de expansão da economia. A evolução do consumo das famílias, ao longo do tempo, pode ser visualizada no Gráfico 1, cujos dados foram retirados do sítio do Banco Central e do IBGE, em 2014, bem como da representação gráfica de Além e Giambiagi (1997, p. 09).
Gráfico 1: A evolução do consumo das famílias de 1980 a 1997

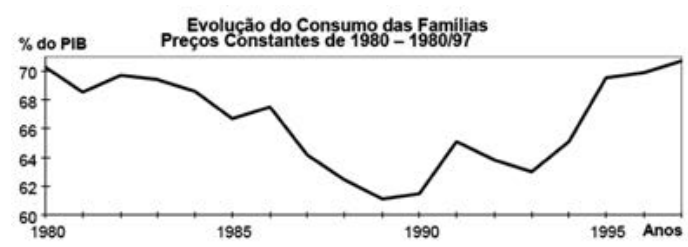

Fonte: IBGE (2014b); BANCO CENTRAL (2014a); ALÉM; GIAMBIAGI (1997, p. 09).

De acordo com os dados, pode-se verificar que o consumo das famílias caiu significativamente ao longo dos anos 1980. Para o Banco Central e o IBGE, esse movimento é resultado da queda do salário real no período, devido ao efeito combinado da redução dos níveis de renda decorrentes do período recessivo.

Também, a crise da década de 1980 aprofundou o desequilíbrio social, pois foi marcada pela aceleração inflacionária, que afetou principalmente os segmentos de menor poder aquisitivo, e pelas elevadas taxas de desemprego. De acordo com a Fundação Getúlio Vargas, a média mensal de aumento de preços, medida pelo Índice Geral de Preços, passou de 2,4\% em 1970-1979 para 7,7\% em 1980-1984, atingindo $16,2 \%$ em 1980-1989. Nesse contexto, surgiram os congelamentos e os tabelamentos de preços, visto que os preços chegavam a ser reajustados várias vezes ao dia.

Ainda, com a evolução da crise da dívida do Estado, o governo passou, sistematicamente, a contribuir de forma negativa para a formação da poupança, absorvendo a poupança privada para cobrir o deficit em suas contas. A Tabela 2, com dados retirados da série histórica de 1947 a 1999, formulada pelo IBGE, no documento Estatísticas do Século XX, mostra o montante de poupança absorvida pelo governo. 
Tabela 2: A participação da poupança do governo e da poupança externa na poupança bruta total no Brasil, de 1947 a 1999

\begin{tabular}{r|c|c|c}
\hline Período & $\begin{array}{c}\text { Poupança do governo/ } \\
\text { Poupança total (\%) (A) }\end{array}$ & $\begin{array}{c}\text { Poupança do externa/ } \\
\text { Poupança total (\%) (B) }\end{array}$ & $\begin{array}{c}(\mathrm{A})+(\mathrm{B}) \\
(\mathrm{C})\end{array}$ \\
\hline $1947-1959$ & 13,2 & 4,7 & 17,9 \\
$1960-1969$ & 6,0 & 3,4 & 9,3 \\
$1970-1979$ & 17,7 & 15,0 & 32,7 \\
$1980-1989$ & $-6,4$ & 9,4 & 3,0 \\
$1990-1999$ & $-4,0$ & 10,5 & 6,5 \\
\hline
\end{tabular}

Fonte: IBGE (2014c).

O Gráfico 2 mostra a relação das reservas sobre a dívida externa total no período de 1970 a 2009. Pode-se verificar que a década de 1980 apresentou a menor relação entre essas grandezas. Assim, necessitando obter recursos para a cobertura dos pesados encargos da dívida externa contraída anteriormente, o governo adotou várias medidas almejando a geração de reservas.

Uma dessas medidas foi a política de incentivo para a expansão das exportações.
As exportações, de fato, cresceram consideravelmente em relação à década anterior. Porém, as medidas produziram, também, efeitos negativos. Adotou-se um sistema de incentivo aos exportadores que envolvia extenso subsídio, o que onerava as finanças públicas. E promoveu-se, em 1983, uma "maxidesvalorização" de $30 \%$ da moeda nacional, o que aumentou as pressões inflacionárias. O Gráfico 2 (uma série de 1970 a 2009), coletado em 2014, com base em dados do Banco Central, representa o exposto:

Gráfico 2: A relação das reservas cambiais em relação à dívida externa total

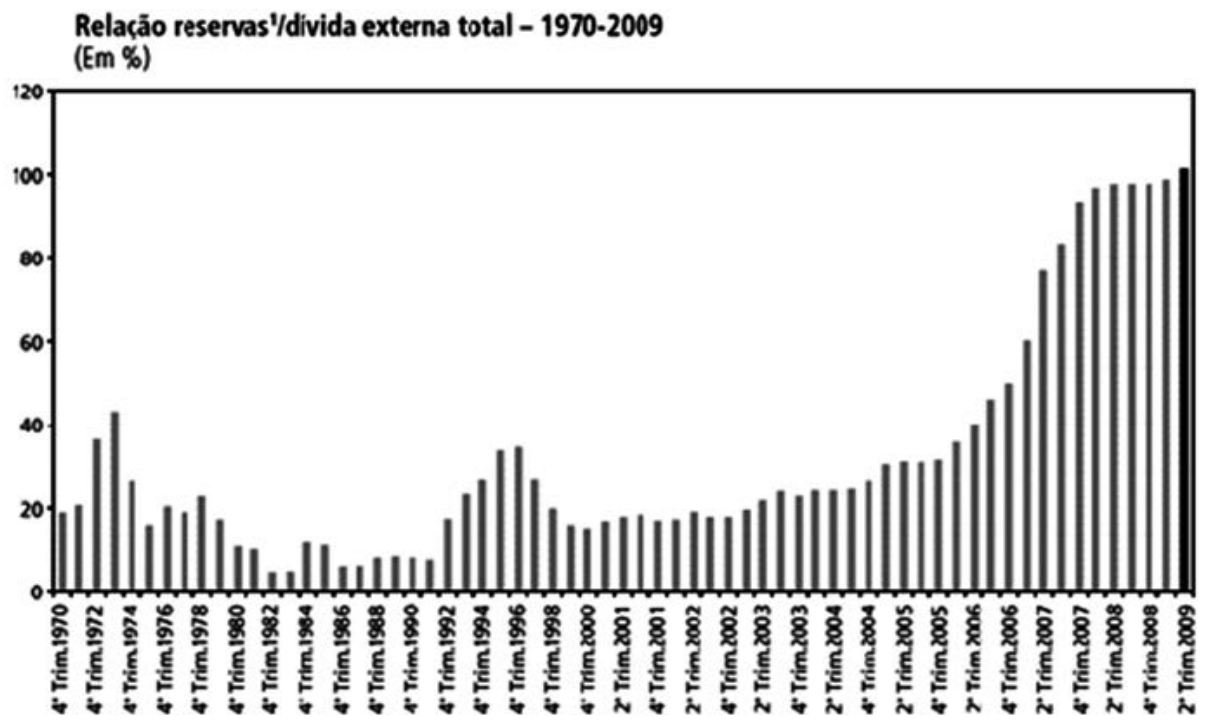

Fonte: BANCO CENTRAL (2014b). 
Logo, o grande destaque para o ambiente econômico dos anos 1980 foi a crise da dívida externa. Ela impediu o acesso a novas linhas de crédito, levou à deterioração das finanças públicas e à inflação, o que, por sua vez, orientou a implementação de políticas de ajuste.

Com esse cenário macroeconômico, no ambiente privado interno, a prioridade das empresas passou a ser a adoção de estratégias defensivas e de curto prazo para enfrentar um cenário marcado por encarecimento e redução do crédito, contenção da demanda, congelamentos de preços, reformas monetárias, mudanças de regras contratuais, entre outros, que marcam a economia brasileira nos anos de 1980 até o início dos anos de 1990.

Como consequência da crise da década de 1980 para os dias atuais, pode-se destacar a visão de Bacha e Bonelli (2004). Os autores demonstram, como se observa no Gráfico 3, que, desde a crise de 1980, o crescimento econômico do Brasil perdeu o vigor da sua trajetória, o que marcou os anos entre 1950 e 1980.

Gráfico 3: Crescimento econômico brasileiro em percentual

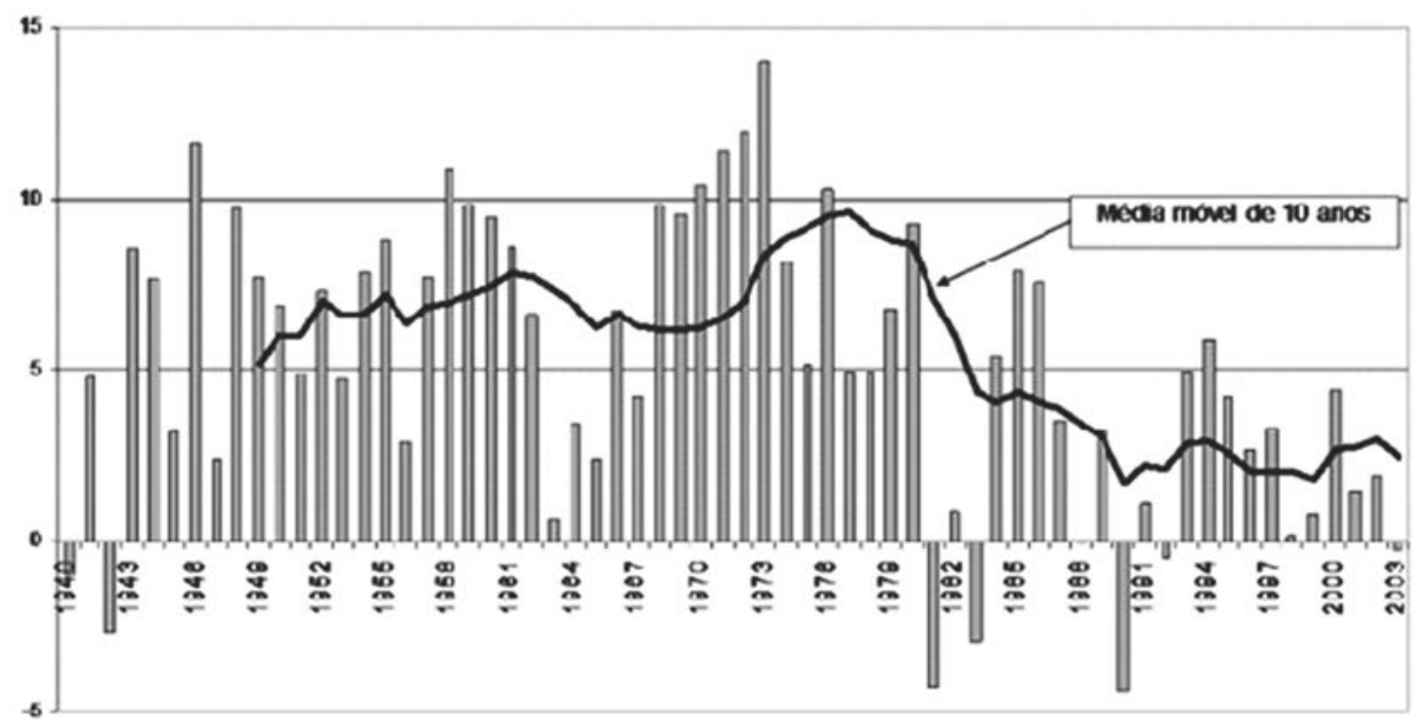

Fonte: BACHA; Bonelli (2004).

Integrando a conjuntura econômica, no âmbito político e social, no ano de 1988, o território passou por uma intensa fragmentação. Com a nova Constituição, entre 1988 e 2000, 253 novos municípios foram criados no estado do Rio Grande do Sul e, de fato, há um crescimento na Justiça Federal nessa mesma época, o que mostra um dos motivos dessa interiorização motivada pelas de- mandas de uma conjuntura de instabilidade econômica intrarregional afetada pela crise nacional e mundial.

No caso de Passo Fundo, como em todo o país, a década de 1980 iniciou-se com uma política de retorno à democracia. Muitos exilados políticos foram convidados a voltar ao país com o final do regime militar. Em termos culturais, foram inauguradas a TV Umbu e a 
Rádio Atlântida FM. Em 1982, aconteceram as eleições municipais, saindo vencedor o Partido Democrático Social. Os anos de 1983 e 1984 foram marcados pelo fim do mandato do general João Figueiredo e pela esperança de muitos civis e estudantes que saíram às ruas em passeatas pela campanha Diretas-Já! (campanha por uma eleição com votos diretos, voto popular). Perdendo essa batalha, toda a sociedade movimentou-se para reverter a situação com a Assembleia Nacional Constituinte de 1988 e, nesse mesmo ano, houve uma nova eleição municipal dando vitória a Airton Dipp e Carlos Annes (Partido Democrático Trabalhista).

\section{Quantificação dos litígios judiciais predominantes no período de criação da subseção de Passo Fundo}

No período da criação da subseção de Passo Fundo, ${ }^{3}$ houve uma grande demanda de ações contra entidades importantes, como Instituto Nacional do Seguro Social, Caixa Econômica Federal (CEF) e Fazenda Nacional. Com a totalidade de 219 processos analisados, do período de 1987 a 1990, observa-se que se tratam, em sua maioria, de processos relacionados diretamente ou indiretamente com a instável conjuntura econômica e social do país, a exemplo do caso de revisão ou concessão dos benefícios previdenciários de aposentadorias do Instituto Nacional do Seguro Social, das correções monetárias do Fundo de Garantia por Tempo de Serviço (FGTS) e de poupanças da Caixa Econômica Federal e do empréstimo compulsório sobre veículos automotores ou combustíveis da Fazenda Nacional.
Durante todos esses anos, a sociedade sofreu com as mudanças de constituições. Com isso, aposentados da Previdência continua tiveram muitos prejuízos, perdendo o valor de seus benefícios em função das mudanças propostas pelo governo, mas não somente os aposentados, como também qualquer cidadão, perderam direitos com a nova reestruturação do governo. Talvez esteja aqui o motivo que procurávamos para saber por que houve tanta demanda de processos na Justiça nesse período. Não houve mudanças apenas no governo do Brasil, mas também nos estados, cidades e municípios, mudanças de cunho político, que afetaram a economia, a religião, a cultura e, principalmente, os cidadãos, que passaram cada vez mais a lutar pelos seus direitos por meio de uma justiça competente e desvinculada do Executivo. Nesse sentido, faz-se necessário realizarmos uma breve contextualização histórica desses segmentos, pois nos indicam as conjunturas socioeconômicas e políticas de sua criação e mudanças na história brasileira.

A Caixa Econômica Federal é uma instituição sob a forma de empresa pública do governo federal brasileiro, com patrimônio próprio e autonomia administrativa, com sede em Brasília (DF) e filiais em todo o território nacional. É uma pessoa jurídica autônoma, vinculada ao Ministério da Fazenda. A Caixa tem sido sinônimo de garantia para milhares de poupadores e assegurou os depósitos de seus clientes por quase 130 anos ininterruptos, até a chegada ao poder do presidente Fernando Collor de Mello, que, por decreto, mandou confiscar todos os ativos financeiros da população brasileira, inclusive as tão fiéis cadernetas de poupança. 
Em 12 de janeiro de 1861, D. Pedro II assinou o Decreto $\mathrm{n}^{\mathrm{o}} 2.723$, que sancionava a criação de uma Caixa Econômica e de um Monte de Socorro, na Corte, cuja finalidade maior, naquele momento, era conceder empréstimos e estimular o hábito de poupar entre a população, até então tida como imprevidente e perdulária. A Caixa, como instituição pública participante dos principais momentos da história do Brasil, a partir do Segundo Reinado, nasceu de pequenas poupanças de escravos que almejavam a liberdade por meio de cartas de alforria, de senhoras que penhoravam suas joias mais singelas e de pequenos comerciantes que fugiam da usura da agiotagem, ao tomarem empréstimos com juros bem menores.

A Caixa, ao longo de seus quase 150 anos, é a instituição pública de referência para os segmentos sociais menos privilegiados e mais numerosos no Brasil. Ela é a instituição oficial na disponibilização do crédito imobiliário e a instituição oficial que administra vários fundos e programas sociais do governo federal brasileiro. Dentre os principais fundos e programas sociais administrados pela Caixa estão: o FGTS, fundo que prioriza o atendimento aos setores de habitação e saneamento básico, o Proframa Integração Social, o seguro-desemprego, o Bolsa Família, o Fundo de Amparo ao Trabalhador, entre outros. Além desses programas, a Caixa realiza operações normais de um banco, pois ainda oferece produtos como o penhor. Nesse tipo de produto, a ideia é permitir certa tranquilidade a quem dispuser de economia para guardar ou necessita de empréstimos a juros mais acessíveis. Assim, pode-se perceber que a Caixa Econômica
Federal é de fato a instituição social oficial do Brasil, pois atende às áreas de habitação, saneamento, infraestrutura e prestação de serviços. Desse modo, exerce papel fundamental para o desenvolvimento social, como a maior promotora de desenvolvimento urbano e de justiça social, ao priorizar o atendimento àquela população de menor renda e mais carente de recursos públicos.

Ainda, a Caixa também administra e distribui os principais programas de geração de renda do país. Em 2003, o governo federal achou por bem unificar todos esses programas - Bolsa Escola, do Ministério da Educação, Bolsa Alimentação, do Ministério da Saúde, Auxílio-Gás, do Ministério de Minas e Energia, e o mais divulgado programa de distribuição de renda, o Bolsa Família.

O Instituto Nacional do Seguro Social (INSS) é uma autarquia do governo federal do Brasil vinculada ao Ministério da previdência social, que recebe as contribuições para a manutenção do Regime Geral da previdência social, sendo responsável pelo pagamento de aposentadoria, pensão por morte, auxílio-doença, auxílio-acidente, entre outros, para aqueles que adquirem o direito a esses benefícios segundo o previsto em lei. Além do regime geral, os estados e municípios podem instituir os seus regimes próprios financiados por contribuições específicas.

No ano de 1923, com a Lei Eloy Chaves, foi implantada, no Brasil, a previdência social, na forma de pensão e caixas de aposentadoria, contemplando apenas algumas classes de trabalhadores. Mas, foi, a partir dessa lei, que surgiram outras caixas de aposentadorias e pensões, sendo os benefícios estendidos a praticamente todas as catego- 
rias de trabalhadores urbanos. A partir de 1933, a Previdência iniciou uma nova fase com a criação dos Institutos de Aposentadorias e Pensões. Entretanto, como cada instituto operava de forma distinta, fez-se necessária a uniformização da legislação aplicável à previdência social, bem como a unificação administrativa.

Somente em 1960, com a Lei Orgânica da previdência social, houve a unificação das leis previdenciárias. Restava, portanto, a unificação administrativa, fato que ocorreu somente em 1966, com a fusão dos Institutos de Aposentadoria e Pensão (IAPs), sendo criado o Instituto Nacional de previdência social (INPS). Na década de 1970, surgiram inovações importantes na legislação previdenciária, entre elas a criação do salário-família e do salário-maternidade, que passaram a constar no rol dos benefícios previdenciários. A reunião dessas, e de outras formas legais surgidas, resultou na criação da Consolidação das Leis da previdência social (CLPS), em 1976.

Em 1977, visando reestruturar a previdência social e as formas de manutenção e concessão dos benefícios e serviços, além de reorganizar a gestão administrativa, financeira e patrimonial, foi criado o Sistema Nacional de Previdência e Assistência Social (Sinpas), abrangendo os seguintes órgãos: INPS, Instituto de Administração Financeira da Previdência e Assitenência Social (Iapas), Instituto Nacional de Assistência Médica da previdência social (Inamps), Fundação Nacional do Bem-Estar do Menor (Funabem), Legião Brasileira de Assitência (LBA), Central de medicamentos (Ceme) e Dataprev. Com a Constituição Federal de 1988, foi ins- tituída a Seguridade Social, com base no tripé Saúde, Previdência e Assistência Social, compreendendo aposentadorias, pensões, auxílio-doença, salário-maternidade, salário-família, auxílio-reclusão, Sistema Único de Saúde, além de outros direitos garantidos pelo Regime Geral da previdência social.

Já em 1990, foi criado o Instituto Nacional do Seguro Social (INSS), órgão resultante da fusão entre o INPS e o Iapas, com a atribuição de gerenciamento das contribuições sociais destinadas ao financiamento da previdência social, além de assegurar ao trabalhador o direito do recebimento dos benefícios por ela administrados. Os outros órgãos que faziam parte do Sinpas foram paulatinamente sendo extintos: o Inamps em 1993, a LBA e a Funabem em 1995, e o Ceme em 1997. A Dataprev permanece atuando na prestação de serviços de processamento de dados aos órgãos do Ministerio de Previdência e Assistência Social. Em 1994, o reajuste dos benefícios previdenciários foi desatrelado do reajuste do salário-mínimo. Logo em seguida, foi criado o Fator Previdenciário. Trata-se de uma regra matemática que diminui o valor do benefício: quanto mais jovem o trabalhador alcança o tempo de se aposentar, menos irá receber.

Em dezembro de 1998, uma emenda constitucional provocou diversas mudanças no sistema de previdência social, das quais se destaca: - determinou que o benefício salário-família seria devido somente ao trabalhador de baixa renda; - proibiu qualquer trabalho para menores de 16 anos, salvo na condição de aprendiz, a partir dos 14 anos; - estabeleceu novas regras para concessão de benefícios previdenciários a funcionários 
públicos; - criou diretrizes para o regime de previdência privada; ainda, nos dias atuais, a previdência continua passando por constantes reformulações.

Nessa perspectiva, o Ministério da Fazenda é o órgão que, na estrutura administrativa da República Federativa do Brasil, cuida da formulação e da execução da política econômica nacional, da administração fazendária da União, por meio da Secretaria do Tesouro Nacional e da administração superior da estrutura fiscal federal, por meio de sua Secretaria da Receita Federal.

A matriz histórica da Fazenda Nacional é remetida à Lei $\mathrm{n}^{\circ} 2.642$, de 9 de novembro de 1955, quando houve a criação da Procuradoria-Geral da Fazenda Nacional (PGFN), na forma atualmente conhecida, em substituição à Procuradoria-Geral da Fazenda Pública. Instituída como órgão de consultoria jurídica do Ministério da Fazenda, à PGFN era atribuído, principalmente, examinar e fiscalizar os contratos de interesse da União, apurar e inscrever a dívida ativa federal para fins de cobrança judicial e cooperar com o Ministério Público da União quanto à justiça comum (art. $\left.1^{\circ}\right)$.

O Decreto-Lei $n^{\circ} 147$, de 3 de fevereiro de 1967, estabeleceu a segunda lei orgânica da PGFN. Esse diploma legislativo fixou competências até hoje mantidas pelos demais atos normativos que o sucederam, na mesma direção do que previa a Lei $\mathrm{n}^{\circ}$ 2.642, de 1955, estabelecendo o seguinte: a) a vinculação administrativa da PGFN como órgão do Ministério da Fazenda responsável pela prestação de serviços jurídicos da pasta; b) a atribuição de apurar e inscrever, para fins de cobrança judicial, a dívida ativa da
União (AGU), tributária ou de qualquer outra natureza; c) a sua atuação nacional por força da descentralização do órgão.

Com a promulgação da Constituição da República de 1988, houve uma mudança significativa da Procuradoria-Geral da Fazenda Nacional quanto à sua vinculação exclusiva ao Ministério da Fazenda. A PGFN passou a integrar a nascente Advocacia-Geral da União, órgão criado para defender, judicial ou extrajudicialmente, os interesses da União.

A Lei Complementar $\mathrm{n}^{\circ} 73$, de 10 de fevereiro de 1993, que institui a Lei Orgânica da Advocacia-Geral da União, previu, expressamente, a subordinação técnica e jurídica da PGFN ao Advogado-Geral da União, confirmando a finalidade do legislador constituinte em vincular a Procuradoria como órgão da AGU, responsável pela atuação na área fiscal. Com isso, a PGFN tornou-se órgão de direção superior da Advocacia-Geral da União e suas atribuições residem, principalmente, na representação da União em causas fiscais, na cobrança judicial e administrativa dos créditos tributários e não tributários e no assessoramento e consultoria no âmbito do Ministério da Fazenda.

Na Tabela 3, constam alguns dados dos processos pesquisados na Justiça Federal do Rio Grande do Sul, subseção de Passo Fundo: 
Tabela 3: Quantificação dos litígios judiciais predominantes no período de criação da subseção de Passo Fundo

\begin{tabular}{|c|c|c|c|}
\hline Entidades & Ano & Quantidade & Assunto do processo \\
\hline \multirow{3}{*}{ Caixa Econômica Federal } & $1987 / 1988$ & 17 & $\begin{array}{l}\text { Direito civil e outras matérias do } \\
\text { Direito Privado }\end{array}$ \\
\hline & 1989 & 34 & $\begin{array}{l}\text { Direito civil e outras matérias do } \\
\text { Direito Privado }\end{array}$ \\
\hline & 1990 & 20 & $\begin{array}{l}\text { Direito civil e outras matérias do } \\
\text { Direito Privado }\end{array}$ \\
\hline \multirow{3}{*}{ Instituto Nacional do Seguro Social } & 1987 & 13 & $\begin{array}{l}\text { Direito civil e outras matérias do } \\
\text { Direito Privado }\end{array}$ \\
\hline & 1989 & 37 & $\begin{array}{l}\text { Direito civil e outras matérias do } \\
\text { Direito Privado }\end{array}$ \\
\hline & 1990 & 4 & $\begin{array}{l}\text { Direito civil e outras matérias do } \\
\text { Direito Privado }\end{array}$ \\
\hline \multirow{3}{*}{ Fazenda Nacional } & 1987 & 13 & $\begin{array}{l}\text { Aquisição de veículos automotores, } \\
\text { combustíveis, repetição de indébito, } \\
\text { empréstimo compulsório }\end{array}$ \\
\hline & 1989 & 60 & $\begin{array}{l}\text { Aquisição de veículos automotores, } \\
\text { combustíveis, repetição de indébito, } \\
\text { empréstimo compulsório }\end{array}$ \\
\hline & 1990 & 21 & $\begin{array}{l}\text { Aquisição de veículos automotores, } \\
\text { combustíveis, repetição de indébito, } \\
\text { empréstimo compulsório }\end{array}$ \\
\hline
\end{tabular}

Fonte: elaboração da autora, com base nos estudos dos processos localizados no arquivo da Justiça Federal subseção Passo Fundo.

Sabe-se que a competência da Justiça Federal é de julgar processos de empresas federais e de qualquer litígio que corresponda às alçadas nacionais, mas os dados da Tabela 3 demonstram, efetivamente, como a conjuntura política, econômica e social brasileira, na década de 1980, afetou a vida cotidiana dos cidadãos.

Nos processos judiciais envolvendo a Caixa Econômica Federal, na maioria das peças da amostragem estudada, predominam como autores, os cidadãos ou peque- nas empresas - sociedade - e, obviamente, a CEF - Estado - como réu. O foco dos litígios é a iniciativa dos cidadãos em pagar seus empréstimos em juízo, renegociação de empréstimos/dívidas e, principalmente, revisão do reajuste das prestações (financiamento) da casa própria. Outro elemento comum dos processos é a sentença favorável ao autor.

Um exemplo é o Processo $n^{\circ}$ 90.1200121-8; Classe: Ação Cautelar; Autor: Clori José Benazzi; Réu: Caixa Econômica 
Federal - CEF; Ano: 1990 - 1994, o suplicante é mutuário da suplicada através do contrato de financiamento firmado em 29.12.82, para a aquisição de um imóvel nele descrito; este vinha pagando corretamente suas prestações, até que, em julho de 1983, foi surpreendido com o inadimplemento da cláusula de correção de prestação, cujo aumento encontrava-se amarrado à alteração do salário mínimo através do Plano de Equivalência Salarial RC 36/69. Sendo que o salário mínimo, nos anos de 1982/1983, foi majorado em $109.4 \%$, enquanto que a prestação foi corrigida em $130,4 \%$, e, no ano seguinte, houve aumento desigual novamente, tal aumento foi considerado ilegal pelos tribunais do país. Sendo que no contrato havia uma modalidade de correção, porém, ela foi alterada.

Pede que se digne Vossa Excelência, defira, inaudita altera pars, liminar determinando a sustação do leilão do imóvel do autor, pois o mesmo não é "caloteiro", e não quer perder seu imóvel (Núcleo de Documentação Histórica e Jurídica; origem: Justiça Federal do Rio Grande do Sul Subseção Passo Fundo).

Por fim a réu querereu a extinção da ação com baixa na distribuição, pois o autor pagou os honorários diretamente na CEF. Encontram-se observações no corpo do processo que dizem que o autor, sendo analfabeto, sofreu ameaças do banco, para que parasse a ação.

O que se constata, especificamente, nesses processos, é o resultado da instabilidade econômica da política fiscal e tributária pela qual passava o país no período. Como podemos observar no Processo No 87.0010165-6; Classe: Ação Diversa/ Ação declaratória
Negativa; Autor: Rodoviário Schio LTDA; Réu: Fazenda Nacional; Ano: 1987 - 2003, no qual registra-se que, por meio da Lei Complementar $n^{\circ}$ 07/1970, foi criado o PIS sobre o imposto de renda (PIS dedução) na base de $5 \%$ do imposto de renda e de $5 \%$ a ser pago com recursos próprios (PIS repique). A partir de 01.07.88, por força dos decretos-leis n. ${ }^{\circ} 2.445$ e $2.449 / 88$, a contribuição do transporte rodoviário de cargas - atividade a que se dedica a peticionária - passou a ser de $0,65 \%$ mensal sobre a receita-operacional bruta. Antes, o recolhimento era semestral, passou agora, após o intervalo de um trimestre, a mensal. Ou seja, além de pagar mais do que já se pagava, o intervalo diminuiu. $\mathrm{O}$ autor cita o art. 43, inciso $X$, para provar que os decretos-leis feririam a Constituição, mesmo o PIS sendo um tributo, ainda assim está ferindo o princípio da anterioridade da lei. Por fim, a ação foi julgada extinta, feito isso com base nos arts. 794, I e 795, do Código de Processo Civil, ou seja, a ausência da apresentação de elementos a demonstrar existência de saldo devedor remanescente indicado pela possibilidade do surgimento de eventuais e identificáveis diferenças, limitando-se, o autor, tão somente à possibilidade de anulação da decisão, em razão da violação do princípio constitucional da ampla defesa.

Por fim, os processos judiciais envolvendo o Instituto Nacional do Seguro Social representam instabilidade, flexibilidade do próprio instituto frente aos problemas sociais do período e inabilidade jurídica diante da nova consolidação das leis de previdência social, própria da questão até os dias atuais. 


\section{Consideracōes finais}

O propósito deste trabalho foi o de contextualizar historicamente a criação e a atuação da Justiça Federal em Passo Fundo, na década de 1980, identificando as motivações para a interiorização da Justiça Federal. Portanto, a partir da análise de conjuntura política, social e econômica nacional, indica-se, sem dúvida, que as motivações para interiorização da Justiça Federal estão ligadas diretamente ao período de grande transição na e da sociedade brasileira, com o fim do regime militar e seu modelo econômico, a partir do qual, consequentemente, as demandas e reivindicações sociais multiplicaram-se. No entanto, o tema não se esgota.

As reflexões em torno da democracia republicana brasileira marcam o final do século XX e o início do século XXI, por isso, não para finalizar a questão, mas para encerrar este artigo, propomos que o direito de valor racional cristalizador de relações sociais e o Judiciário sejam vistos na condição de processo social na aplicação das elaborações legislativas e como a representação concreta de poder na tríade dos três poderes.

Nesse sentido, no direito e na sua historicidade e processualidade reside um potencial à compreensão do Estado, incluída a sociedade civil e a sociedade política.

Ao estudar o Judiciário é possível visualizar o poder do Estado, problematizar e investigar as ações do Poder Executivo na processualidade do tempo histórico, identificar seu poder sobre as forças econômicas, reorganizando e desenvolvendo o aparelho da produção econômica, dando condições à criação de uma nova estrutura, orientada e diri- gida por fatores superestruturais, por meio do Legislativo e do Judiciário, que lhe dão as condições de operacionalizar um projeto de modernização, impulsionar, solicitar, punir e reprimir. Pois, o direito é uma ação política, civilizadora e modernizadora empreendida pela ação ético-política concreta dos homens, situada temporal e espacialmente.

\section{Abstract}

This paper is aimed at contextualising in historical terms the creation and actions of the Federal Justice in Passo Fundo in the 1980s. For that end, a reading is made of the history of the Federal Justice, as part of the Judicial Power, focusing on the analysis of the political and economical context of the south so as to interpret the motives for the interiorisation of the Federal Justice. The aim is to understand the historical context and the perceptions of power of the Federal Justice and its scope, by performing interviews with subjects who took part in the creation of the subsection of the Federal Justice in Passo Fundo, and analysis of the content of institutional documents and judicial proceedings from the 1980s in order to trace the typologies of disputes and how they relate with the end of the decade as a rupture or continuity of a historical context.

Keywords: Federal Justice. Judicial proceedings. Historical and socio-economical context. 


\section{Resumen}

El artículo presenta el objetivo de contextualizar históricamente la creación y actuación de la Justicia Federal en Passo Fundo en la década de 1980. Para eso hemos realizado uma lectura histórica de la Justicia Federal, como un sector del Poder Judiciario, teniendo como centro el análisis de la coyuntura política y económica de la región sur para entender los motivos de la interiorización de la Justicia Federal. Inténtase compreender el contexto histórico y los sentidos del poder de la Justicia Federal, su alcance, realizando entrevistas con sujetos que participaron de la creación de la Justicia Federal subsección de Passo Fundo, el análisis del contenido de documentos institucionales y de los registros de los procesos de la década de 1980 para establecer las tipologías de los litigios y las relaciones con el final de una década como ruptura o continuidad de uma coyuntura histórica.

Palabras clave: Justicia Federal. Procesos judiciales. Coyuntura histórica y socioeconómica.

\section{Notas}

1 Atualmente, pode-se perceber uma mudança generalizada que envolveu um processo de melhorias do funcionamento da justiça, tanto em caráter de trabalho quanto no pensamento de que o próprio público pudesse acessar este sistema com o objetivo de ajudar e facilitar o acesso aos processos. Para tal feito, foi implantado o Sistema de Processo Eletrônico (E-Proc V1) voltado para os processos dos JEFs (Juizados Especiais Federais), inaugurado em 2003, com o intuito de facilitar o acesso, sendo totalmente virtual, com um sistema seguro e permitindo toda a movimentação dos processos pela internet. Anos mais tarde, a Justiça implantou o novo sistema de processo eletrônico, o E-Proc V2, que, assim como o E-Proc V1, demonstra a democratização na prestação jurisdicional.

2 Municípios que hoje são atendidos pela Justiça Federal do Rio Grande do Sul de Passo Fundo: Água Santa, Camargo, Capão Bonito do Sul, Casca, Caseiros, Ciríaco, Coxilha, David Canabarro, Ernestina, Gentil, Ibiaçá, Ibiraiaras, Lagoa Vermelha, Marau, Mato Castelhano, Montauri, Muliterno, Nicolau Vergueiro, Nova Alvorada, Passo Fundo, Pontão, Santa Cecília do Sul, Santo Antônio do Palma, São Domingos do Sul, Sertão, Tapejara, Tupanci do Sul, União da Serra, Vanini, Vila Lângaro, Vila Maria.

3 Para a realização dessa pesquisa, foi feito um mapeamento dos litígios predominantes da época de 1980, sendo analisados 219 processos judiciais desse período, na subseção de Passo Fundo da Justiça Federal.

\section{Referências}

ALÉM, A. C. D.; GIAMBIAGI, F. O desafio de elevar a poupança privada no Brasil. Revista BNDES, n. 8, p. 3-30, dez. 1997.

BACHA, Edmar Lisboa; BONELLI, Regis. Accounting for Brazil`s Growth Experience - 1940 - 2002, Discussion Papers. 1018, Instituto de Pesquisa Econômica Aplicada - IPEA, 2004. Disponível em: <http://ideas.repec.org/p/ipe/ ipetds/1018.html>. Acesso em: 3 fev. 2014.

BANCO CENTRAL DO BRASIL. Banco de dados. Disponível em: <http://www.bcb.gov. br>. Acesso em: 2 fev. 2014a.

Série histórica do demonstrativo de variação das reservas internacionais. Disponível em: <http://www.bcb.gov.br/?RED-SERIERIH>. Acesso em: 2 fev. 2014b.

CONSELHO DA JUSTIÇA FEDERAL. Disponível em: <http://www.cjf.jus.br/cjf>. Acesso em: 12 set. 2013.

INSTITUTO BRASILEIRO DE GEOGRAFIA E ESTATÍSTICA (IBGE). Taxa de crescimento média. Disponível em: <http:// seriesestatisticas.ibge.gov.br/lista_tema. aspx?op=2\&no=1>. Acesso em: 2 fev. 2014. 
JUSTIÇA FEDERAL DO RIO GRANDE DO SUL. Disponível em: <http://www2.jfrs.jus. br/>. Acesso em: 10 ago. 2013.

FUNDAÇÃO GETÚLIO VARGAS (FGV). Informações gerais. Disponível em: <http://bibliotecadigital.fgv.br/site/biblioteca-digital>. Acesso em: 2 fev. 2014.

INSTITUTO BRASILEIRO DE GEOGRAFIA E ESTATÍSTICA (IBGE). Contas regionais: Produto Interno Bruto por unidade da federação. Disponível em: <http://seculoxx.ibge.gov.br/ economicas/contas-nacionais>. Acesso em: 02 fev. 2014a.

. Despesa de consumo das famílias. Disponível em: <http://seriesestatisticas.ibge.gov. br/lista_tema.aspx?op $=2 \& n o=1>$. Acesso em: 2 fev. 2014b.

. Estatísticas do Século XX: participação da poupança. Disponível em: <http://seriesestatisticas.ibge.gov.br/series.aspx?vcodigo $=\mathrm{SCN} 47 \& \mathrm{t}=$ participacao-poupanca-brbruta-renda-disponivel-bruta>. Acesso em: 2 fev. 2014c.

Sistema de Contas Nacionais 2004-2008.

Disponível em: <http://www.ibge.gov.br/ home/estatistica/economia/contasnacionais/2008/default.shtm>. Acesso em: 2 fev. 2014d.

MACHADO, Ironita Policarpo. Perspectivas: Passo Fundo rumo ao século XXI. In: DIEHL, Astor Antônio (Org.). Passo Fundo: uma história, várias questões, Passo Fundo, n. 7, p. 136152. 1998.

MINISTÉRIO DA FAZENDA. Secretaria de Política Econômica. Gasto Social do Governo Central. Brasília, nov. 2003.

NERI, Marcelo. A economia do Brasil nos últimos 40 anos e perspectivas para o futuro. Disponível em: <http://www.cps.fgv.br/ibrecps/ nw/40anos_EconomiaOGlobo_Neri_CPS_ FGV.pdf>. Acesso em: 2 fev. 2014.
SALLES, Manuel Ferraz de Campos. Exposição de Motivos do Decreto n. 848, de 11/10/1890. In: BRASIL. Conselho de Justiça Federal. Justiça Federal: legislação. Brasília: Conselho da Justiça Federal, 1993. p. 13-18.

SANTOS, Jailson Moreira dos. A história da Caixa Econômica Federal do Brasil e o desenvolvimento econômico, social e político brasileiro. In: COSTA, Juliana Camargos et al. $O$ desenvolvimento econômico brasileiro e a Caixa: trabalhos premiados. Rio de Janeiro: Centro Internacional Celso Furtado de Políticas para o Desenvolvimento: Caixa Econômica Federal, 2011. p.167-181. Disponívelem:<http://www. centrocelsofurtado.org.br/arquivos/image/201111011244400.LivroCAIXA_T_0_167. pdf>. Acesso em: 25 fev. 2015. 